\title{
A METHOD OF MEASURING THE STRESS-STRAIN RE- LATIONS OF WET TEXTILES WITH APPLICATION TO WET RAYONS ${ }^{1}$
}

\author{
By Homer A. Hamm and R. E. Stevens
}

\section{ABSTRACT}

An immersion tank has been developed as auxiliary equipment for a recording stress-strain tester. This tank is built around the lower jaw of the testing machine. It is equipped with suitable stirrer, heater, and heat-control apparatus. The textile, in this method, is fastened in the jaws of the testing machine, liquid is poured in the tank, and after a suitable immersion period the break is made. The results of a series of tests on rayons broken dry, broken dry after wetting in water at $20^{\circ} \mathrm{C}$. and at $100^{\circ} \mathrm{C}$., and broken wet at various temperatures are given.

\section{CONTENTS}

I. Introduction

II. Review of previous work

III. Description of apparatus and test procedure 929

1. Features of method. 929

2. Earlier apparatus and testing procedure

3. Later apparatus......... 930

4. Testing procedure

5. Precautions in making test._. 930

6. Interpretation of stress-strain curves.

7. Discussion of apparatus and procedure

IV. Tests performed_.

V. Summary

VI. Acknowledgments_._. 936

\section{INTRODUCTION}

The stress-strain relations of wet textiles have become of increasing interest with the development of the rayon industry, as rayon is weakened considerably more by wetting than natural fibers. The handling of the usual textiles when wet offers no great difficulties. This is not the case with rayon, however, as producer and processor, laundryman, and consumer may testify. Therefore, a greater knowledge of the physical properties of wet rayons as obtained from a consideration of stress-strain relations is desirable.

\footnotetext{
1 In this paper the term "rayon" denotes synthetic fibers of regenerated cellulose or of cellulose deriva-
} tives. 
An auxiliary apparatus for the complete immersion of the sample during test has been designed for the ordinary testing machine and is adapted to testing wet textiles by the usual methods or by the improved multiple-strand ${ }^{2}$ test. This apparatus and some results obtained on four types of rayon, wet with water at various temperatures, are described herein.

\section{REVIEW OF PREVIOUS WORK}

The methods used by earlier investigators for determining the strength and the elongation of wet textiles were somewhat similar, differing principally in the manner of wetting the samples and in the number of strands broken. P. Krais ${ }^{3}$ gave a few results obtained by using single-strand tests on dry and wet rayons. J. Obermiller and M. Goertz ${ }^{4}$ also broke single strands in their determination of the breaking strength of dry and of wet yarns. P. E. King and E. $\mathrm{N}$. Johnson ${ }^{5}$ made use of the single-strand test for measuring the tenacity and elongation of a wide range of samples of dry and wet rayon yarns. H. D. W. Smith ${ }^{6}$ used the usual multiple strand method; a number of ends were thoroughly wet in water, fastened in the jaws of the testing machine, and broken. D. C. Scott ${ }^{7}$ referred to a machine for testing textiles under water but included no details. R. A. Van Amburg ${ }^{8}$ described a multiple strand test for wet textile yarns, the chief advantage of which is that the break is made as the partially immersed sample is removed from the liquid. He gave a few results on the breaking strength of wet and dry yarns, comparing his method with older ones.

These methods and results will be discussed only in a general way. Tests in which the yarn is partially immersed give the wet breaking strength only for textiles having a lower breaking strength when wet than when dry, and, therefore, this method of testing is not generally applicable. Furthermore, it is impossible to measure the elongation of the wet yarn under these conditions. The handling of wet rayons, as in those methods in which the fiber is wet before placing in the jaws of the testing machine, is to be avoided since rayon fibers are easily changed in physical properties when handled wet. Also evaporation of liquid from the sample before the break is made may affect the results of the test. The results of one investigator are not strictly comparable with those of another as conditions of test and samples tested are not identical.

${ }^{2}$ C. W. Schoffstall and H. A. Hamm, B. S. Jour. Research, 2, p. 871; 1929.

${ }^{3}$ P. Krais, Z. Angew, Chem., 39, p. 196; 1926.

4. Obermiller and M. Goertz, Melliand's Textilb., 7, 163; 1926.

${ }^{5}$ P. E. King and E. N. Johnson, J. Soc. Dyers and Colourists, 44, p. 346; 1928.

${ }^{6}$ H. D. W. Smith, Textile World, r0, p. 2227; 1926.

7 D. C. Scott, Textile World, 74, p. 2623; 1928.

8 R. A. Van Amburg, Textile World, ro, p. 3627; 1926. 


\section{DESCRIPTION OF APPARATUS AND TEST PROCEDURE}

\section{FEATURES OF METHOD}

The method here described was developed to embody the following features: (1) Immersion of the sample until conditions of equilibrium in the fiber have been obtained; (2) complete immersion during test; (3) use of the improved multiple-strand method of test to increase precision, dependability, and speed; (4) adaptability to different thermal conditions and liquids; (5) adaptability to other forms of textiles than yarns; and (6) the expression of results as stress-strain relations.

\section{EARLIER APPARATUS AND TESTING PROCEDURE}

The earlier apparatus for the immersion of samples consisted of a copper immersion tank fitted to the lower jaw of an ordinary testing machine. This lower jaw was fastened in place by allowing its bolt to pass up through the bottom of the tank. The lower jaw served as a nut and the part of its bolt that fastens on the testing machine as the head of the bolt. Rubber washers were used to prevent leaks. In determinations recorded below, this immersion tank was used, fitted on a Scott automatic recording 55 to 110 pound tester of the pendulum type. The time of immersion was selected arbitrarily as one-half hour, and the break was made with the sample immersed in the liquid.

In these tests sampling was done in accordance with the equitension lea method, ${ }^{9}$ which has been shown to give a high degree of precision for dry yarns. Thus the test for the stress-strain relations of wet textiles was made to embody the essential features of tests in the dry condition and the results of wet and dry tests were, therefore, comparable. The equitension lea method has been replaced by the multiple-strand test, ${ }^{10}$ which gives greater speed and adaptability. Tests run by the two methods were in accord.

After the samples had been inserted in the jaws of the testing machine, water at the proper temperature was added, care being taken by pouring the water down one side of the immersion tank, to prevent washing of the fibers. The temperature of the bath was regulated to within $1^{\circ} \mathrm{C}$. by the application of hot plates. This method of temperature control, though accurate, was cumbersome and required much of the operator's time. Difficulty was also experienced in inserting the samples.

\footnotetext{
${ }^{\ominus}$ W. T. Schreiber and H. A. Hamm, Textile World, p. 97; Sept. 24, 1927.

10 The equitension lea method was a step in the development of the multiple-strand test and as such is not a separate method. The study of wet rayons was made simultaneously with the development of the multiple-strand test
} 


\section{LATER APPARATUS}

A new Monel metal auxiliary apparatus, shown in detail in Figures 1,2 , and 3 , was constructed so that all disadvantageous features of the older apparatus were eliminated. Figure 3 is a top view of the immersion tank showing the general arrangement of parts and the shape of the tank. This shape is necessary in order to use a minimum of liquid and to provide clearance for moving parts of the testing machine. The temperature of the bath is electrically regulated. Handholes are provided for inserting the sample.

\section{TESTING PROCEDURE}

The procedure for making a test is as follows:

1. Handhole plates, $A$ and $B$, are removed. (Fig. 2.)

2. The dry sample is inserted, through handhole $A$, in the jaws of the testing machine, as is done in the multiple-strand test. In this test the yarn is wound, equally space, parallel and under uniform tension, upon a split $U$ frame which is held together by a clamp. The first and last ends are fixed to the frame by gummed labels. The lower jaw of the machine is tightened through handhole $B$, and the clamp is then removed from the split $U$ frame.

3. The handholes are covered.

4. Sufficient liquid at the correct temperature is slowly poured into the tank until the fibers are entirely immersed.

5. The stirrer is set in operation and the heaters are turned on.

6. A chart is inserted in the machine to record stress-strain relations.

7. Stirring and heating are discontinued just before a break is to be made.

8. The break is made in the usual way.

9. The water is drained through the petcock.

10. The machine is run to the starting position.

11. The clamps are taken from the jaws after removing the handhole plates.

12. The jaws are dried.

13. The chart is removed, and the apparatus is ready for another test.

The temperature regulator must be set for the proper temperature before starting a series of tests. The faces of the jaws are covered with rubber sheeting to prevent slippage of the fiber when testing.

\section{PRECAUTIONS IN MAKING TEST}

1. The jaws of the testing machine should be dry before inserting the fibers; otherwise some of the fibers may become wet, and consequently all fibers would not be inserted in the same way.

2. The stream of water, as the water is poured into the tank, should be directed away from the yarns. 
B. S. Journal of Research, RPI22

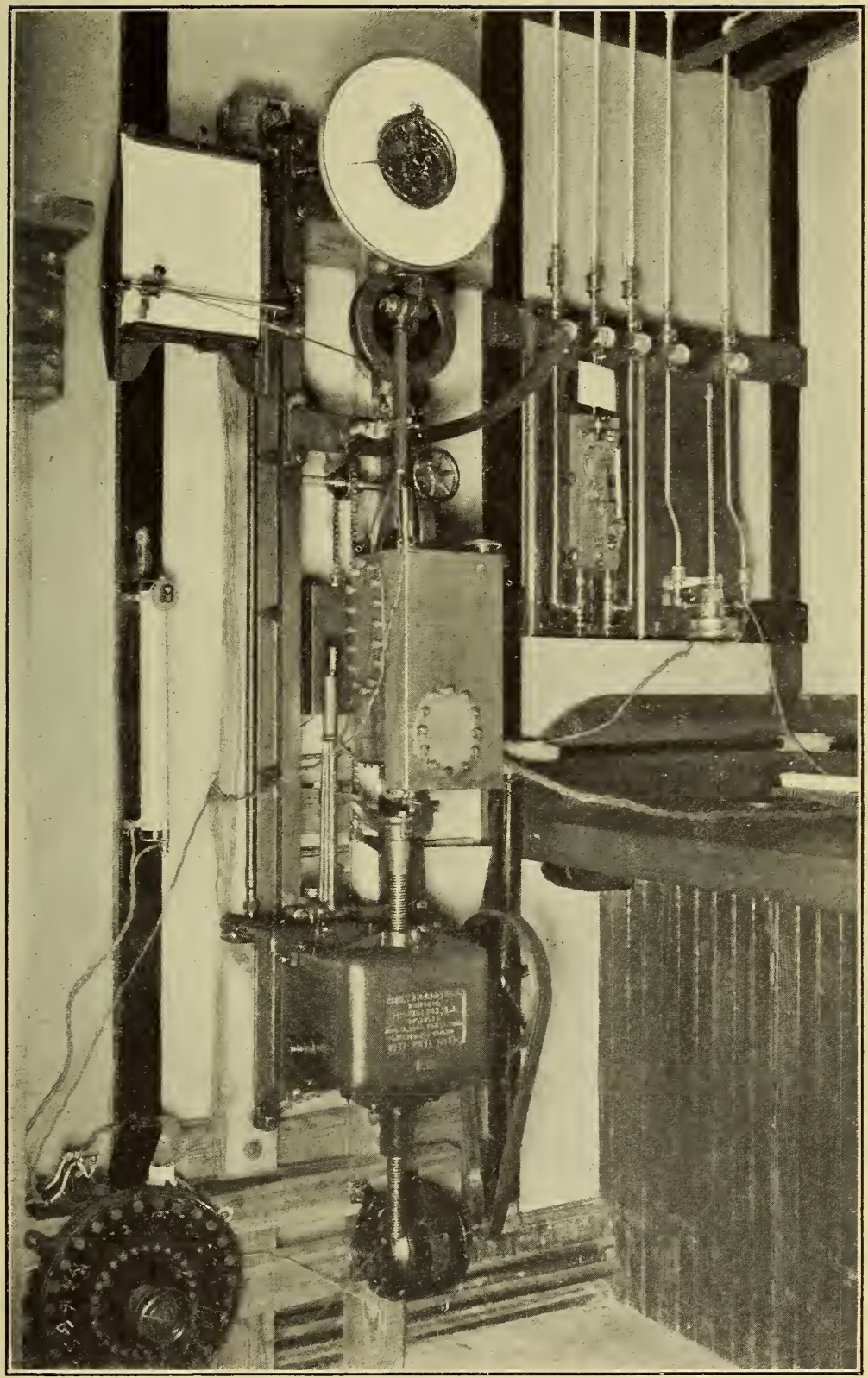

FIGURE 1.-A Axiliary apparatus on the tester ready for operation 


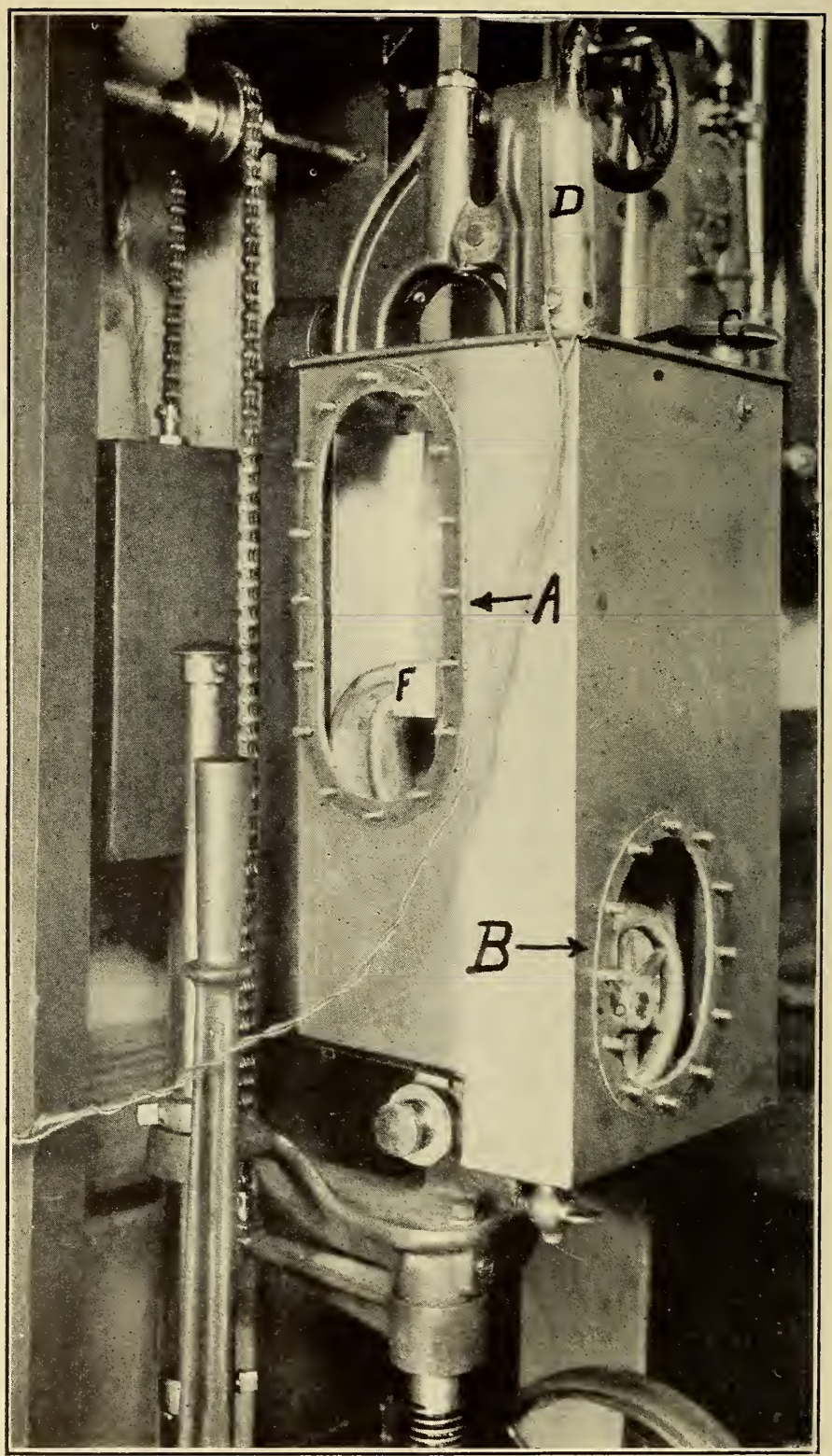

Figure 2.-Left side view of immersion tank with manhole covers removed

$A$, Manhole $A ; B$, manhole $B$; $C$, stirrer; $D$, temperature control; $E$, upper jaw of testing machine; and $F$, lower jaw of testing machine. 
B. S. Journal of Research, RP122

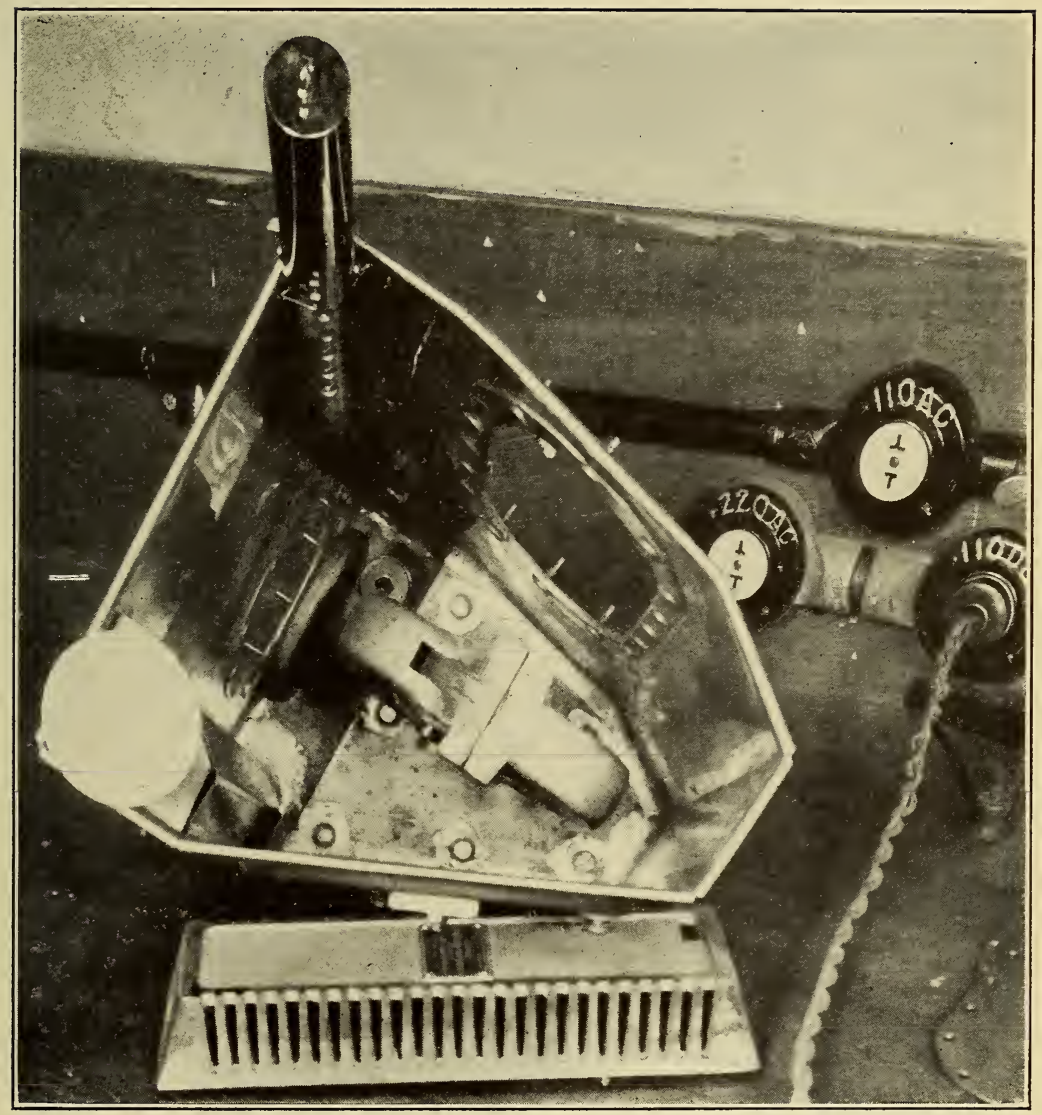

FIGURE 3.-Top view of immersion tank showing inside details 
3. To prevent rusting, the moving parts which are immersed in water should be well oiled.

4. All samples before testing should be conditioned ${ }^{11}$ so that comparable results on the elongation of the yarn upon wetting may be obtained.

\section{INTERPRETATION OF STRESS-STRAIN CURVES}

Considerable information concerning the physical properties of wet yarns can be obtained from the stress-strain curve of each test. Figure 4 is a typical stress-strain curve for wet rayon. The break-

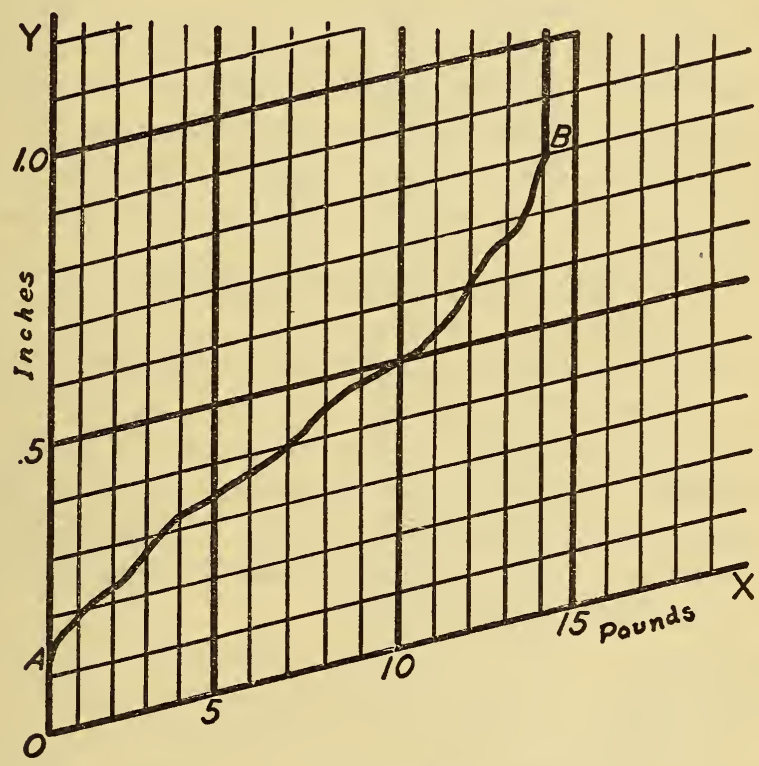

Figure 4

ing load may be read directly. It is the projection on the axis of $X$ of the point $B$ where the curve rises abruptly for the last time. (See fig. 4.) Rayon elongates upon wetting. This elongation of the yarn is the difference in the readings $O$ and $A$ on the axis of $Y . O$ is the zero point and $A$ is the point where the load is first applied to the fibers. The stretch at break is the difference in the readings $A$ and the projection on the axis of $Y$ of the point $B$. Let $D$ represent the initial separation of the jaws. Then the per cent stretch of the wet yarn is given by the following formula:

$$
\text { Per cent stretch }=\frac{B-A}{A+D} \times 100
$$

\footnotetext{
"1 Samples are conditioned by exposing them to air having a definite temperature and humidity until
} the moisture content of the sample reaches equilibrium. 


\section{DISCUSSION OF APPARATUS AND PROCEDURE}

This method, developed primarily for determining the stress-strain curves for rayon yarns, is applicable to all textile yarns and to any cloth. A special problem arises when the textile to be tested contracts when it comes in contact with water. This case can be handled by inserting the sample in the jaw in the regular way and then running the jaws of the machine close enough together so that there will be some slack in the textile after wetting. The test is made as usual, but corrections in calculations have to be made to compensate for the difference in procedure.

The temperature of the bath and the time of immersion are factors which may be adjusted to give test data of interest to the textile trade and to the consumer. Any temperature within an ordinary range and any liquid which has no effect on the apparatus may be used. The results will show the effect of the liquid on the tensile properties of the textile when it is in contact with that liquid at a particular temperature.

\section{TESTS PERFORMED}

A series of tests was made to establish the usefulness of this method and to obtain data on the physical properties of wet rayons. The samples tested represent four types of rayon. The size of yarns was approximately 150 denier, ${ }^{12}$ with the exception of the cuprammonium rayon, which was somewhat finer. These tests were made during the summer of 1927 , and yarns manufactured at a later date might give somewhat different results.

The conditions of tests were those established in the multiplestrand test; namely, the distance between the jaws was 4 inches; the rate of separation of the jaws was 12 inches per minute; and 80 strands were broken for each test. All samples were conditioned at 65 per cent relative humidity and $20^{\circ} \mathrm{C}$. before testing.

The following tests were made:

1. The samples were broken dry.

2. The samples were broken wet at room temperature, and at $60^{\circ}, 70^{\circ}, 80^{\circ}, 90^{\circ}$, and $100^{\circ} \mathrm{C}$.

3 . The samples were wet one-half hour in water at room temperature, dried and broken.

4. The samples were wet in boiling water for one-half hour, dried and broken. The samples were first cooled in water before exposing to the air. 
Tables 1 and 2 and Figures 5 and 6 give the results of these tests.

These results, and those of other investigators, show the weakening of rayon upon wetting. The temperature of the bath has little effect on the breaking strength of regenerated cellulose rayon. As the temperature of the water is increased, the wet breaking strength of the cellulose acetate rayon tested decreases, and its

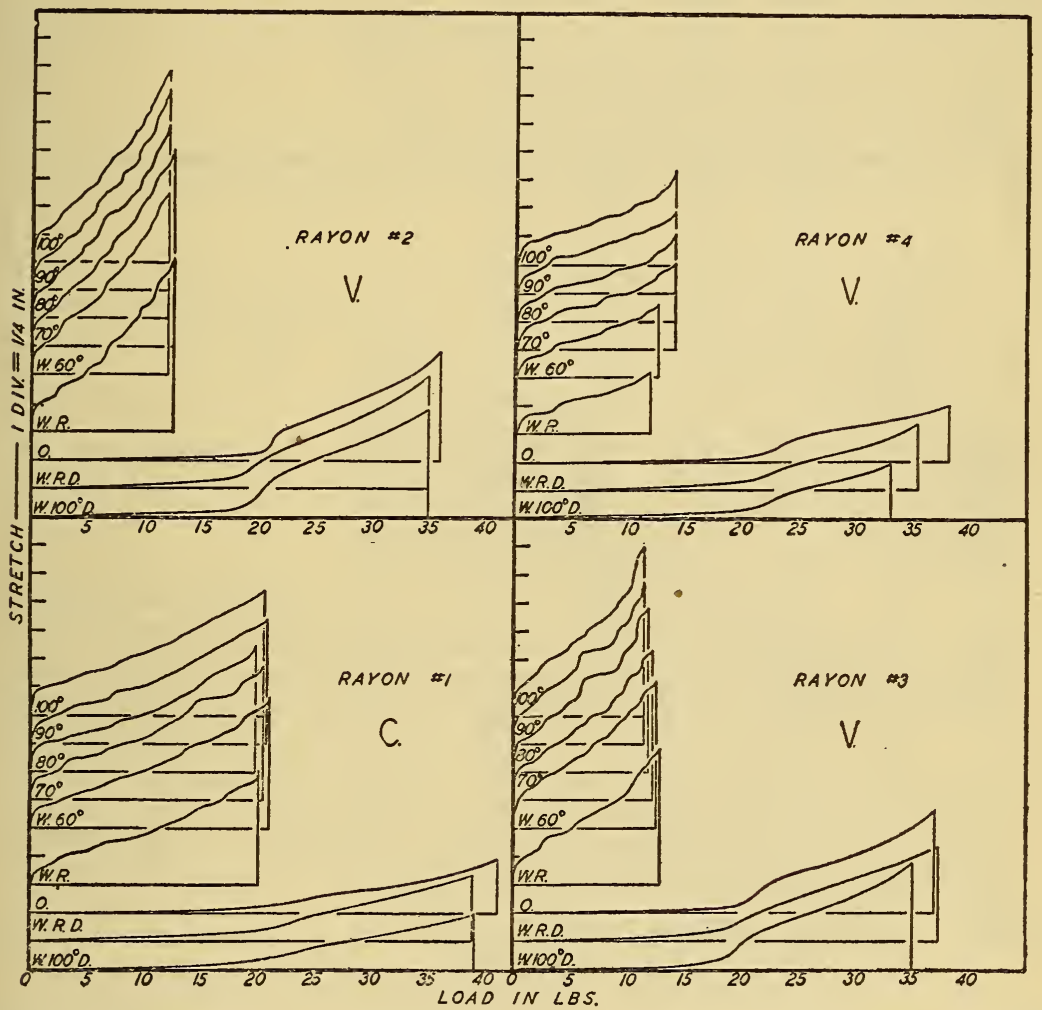

FIGURE 5.-Stress-strain relations of rayons-multiple-strand tests on 80 strands

$W .100^{\circ} \mathrm{D}$., wet sample one-half hour in water at $100^{\circ} \mathrm{C}$.; broken dry. W.R. D., wet sample one-half hour in water at room temperature; broken dry. 0 ., broken dry. W. $R$., broken wet at room temperature. $W .60^{\circ}$, broken wet at $60^{\circ} \mathrm{C}$. $70^{\circ}$ broken wet at $70^{\circ} \mathrm{C}$. $80^{\circ}$ broken wet at $80^{\circ} \mathrm{C}$. $90^{\circ}$, broken wet at $90^{\circ} \mathrm{C} .100^{\circ}$, broken wet at $100^{\circ} \mathrm{C}$.

Note.-Charts on Figures 5 and 6 have been replotted to rectangular coordinates, and in order to avoid confusion a different axis has been used for each curve.

NотE.-Charts on Figures 5 and 6 have been replotted to rectangular coordinates, and in order to avoid confusion a different axis has been used for each curve.

elongation due to wetting and its stretch at break increase. Cellulose acetate rayon also shows definite changes in stress-strain relations when treated for one-half hour in boiling water and broken dry.

Work is now under way to explain these stress-strain relations, and also the peculiar behavior observed in cellulose acetate rayons. 


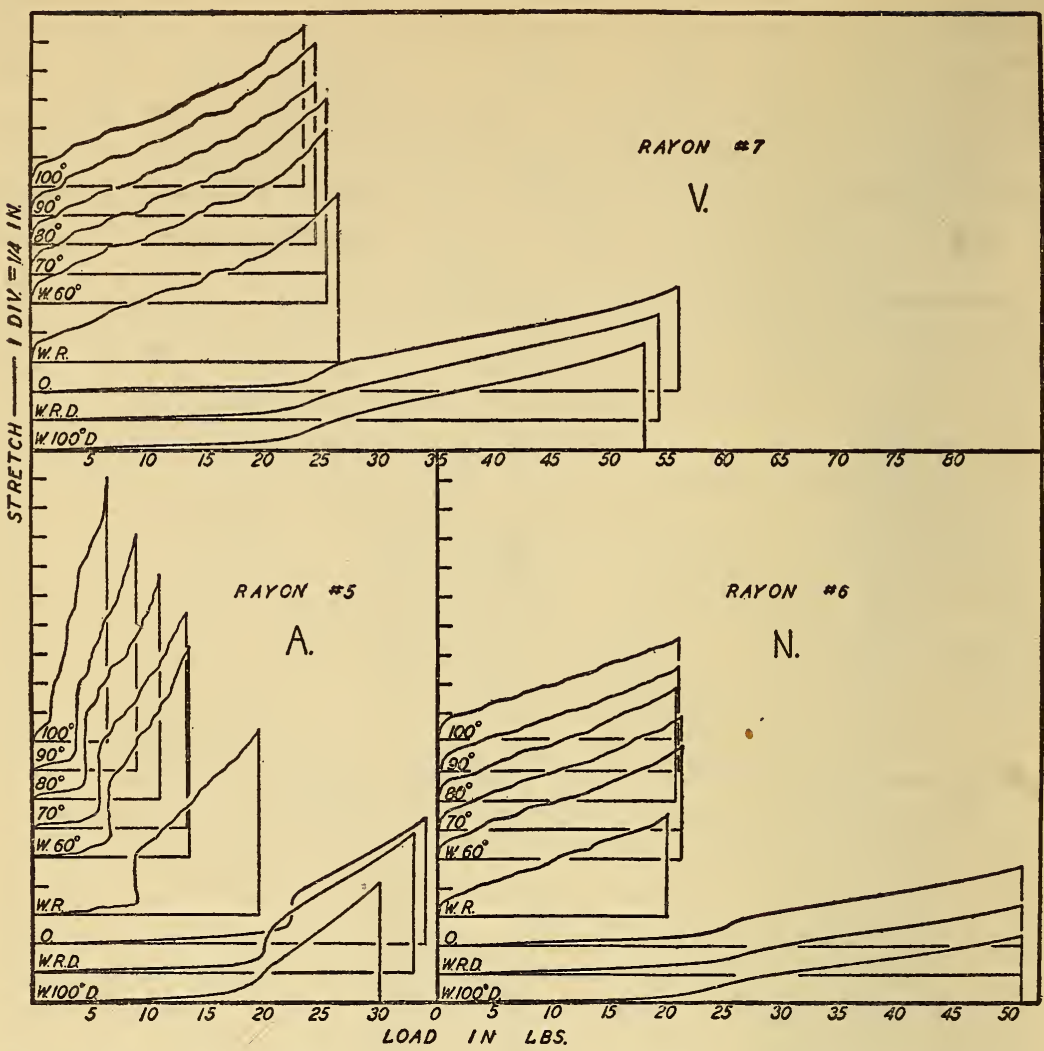

FIGURE 6.-Stress-strain relations of rayons-multiple-strand tests on 80 strands

$W .100^{\circ} \mathrm{D}$., wet sample one-half hour in water at $100^{\circ} \mathrm{C}$., broken dry. W. R. D., wet sample one-half hour in water at room temperature; broken dry. $O$., broken dry. W. $R$., broken wet at room temperature. $W \cdot 50^{\circ}$, broken wet at $60^{\circ} \mathrm{C}$. $70^{\circ}$, broken wet at $70^{\circ} \mathrm{C}$. $80^{\circ}$, wet broken at $80^{\circ} \mathrm{C}$. $90^{\circ}$, broken wet at $90^{\circ} \mathrm{C}$. $100^{\circ}$, broken wet at $100^{\circ} \mathrm{C}$.

TABLE 1.-Effect of wetting on the stress-strain data for dry rayons (80 strands broken)

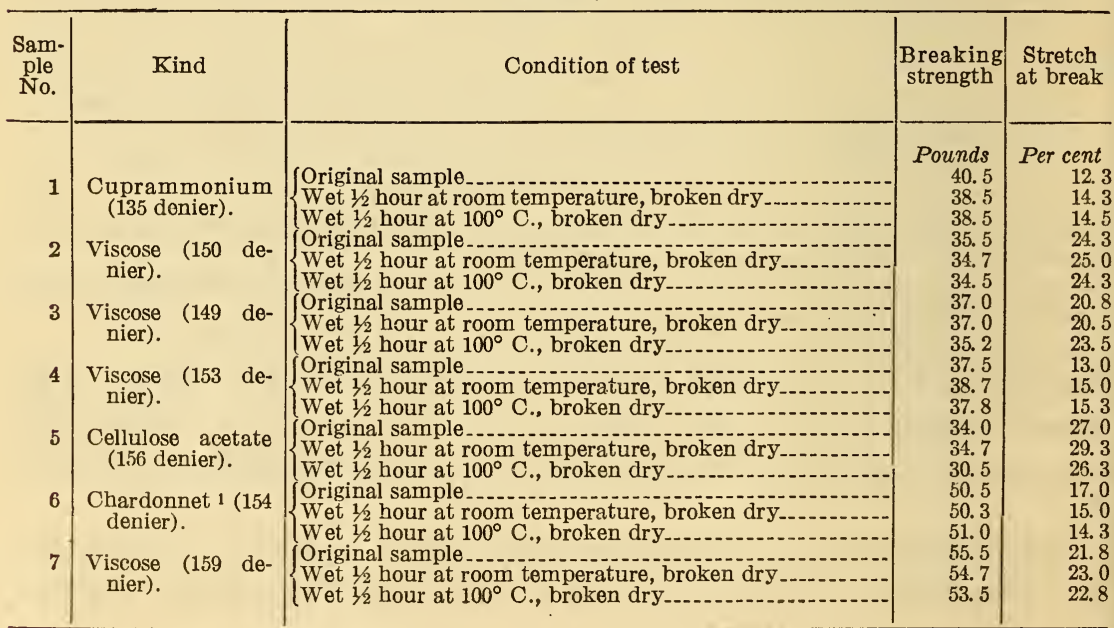

\footnotetext{
1 Commonly called nitrocellulose rayon.
} 
TABLE 2.-Stress-strain data for wet rayons (80 strands broken)

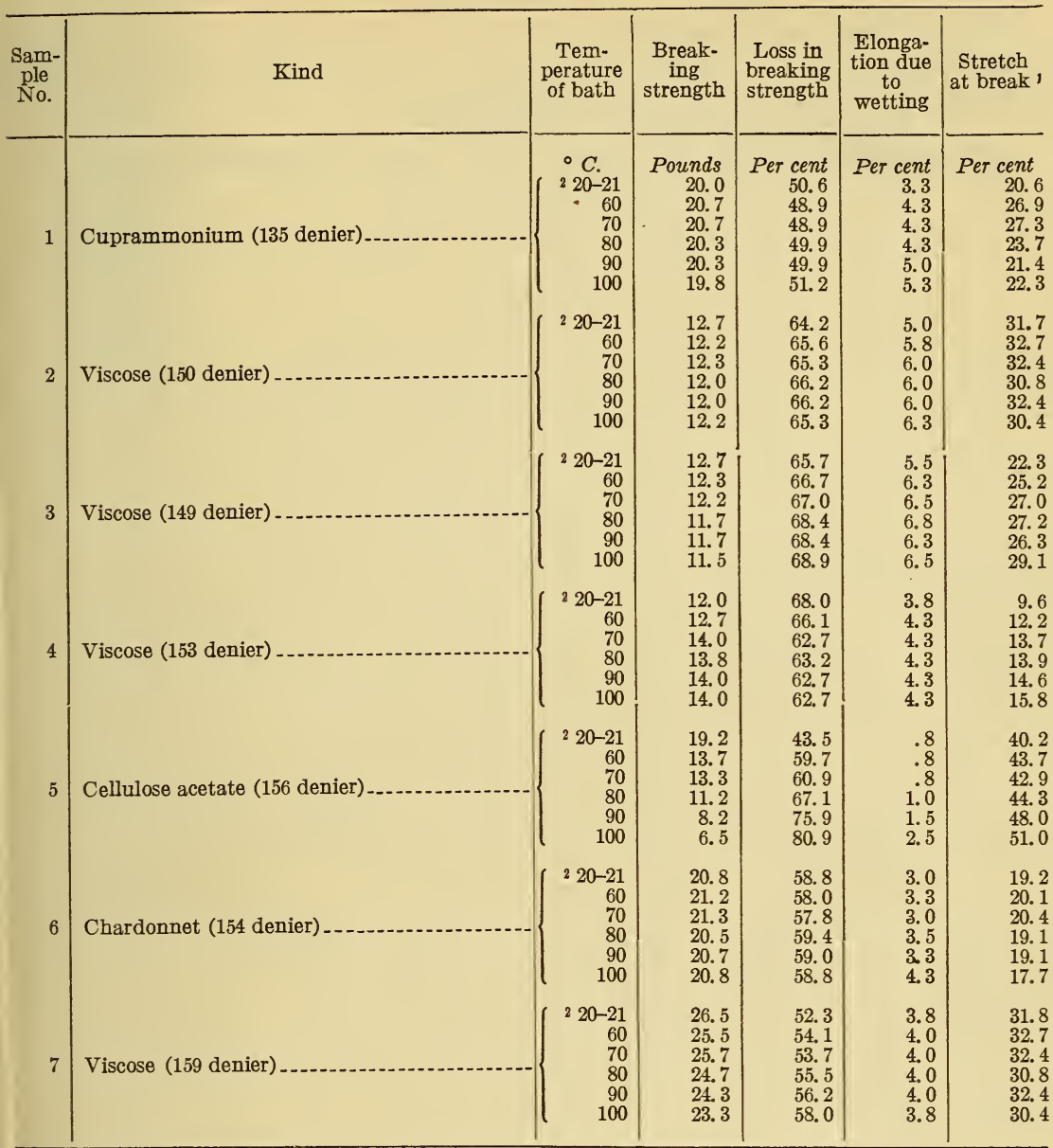

1 This stretch at break does not include the elongation due to wetting. $220^{\circ}-21^{\circ} \mathrm{C}$. is room temperature.

\section{SUMMARY}

A method for determining the stress-strain relations of textiles when wet has been developed. With this method measurements can be made as accurately as those obtained with the multiple-strand test for dry yarns. ${ }^{13}$ The apparatus is so designed that a test may be made over a range of temperatures. The method may be used for all types of textiles, either as yarn or fabrics.

Results are given which show the effect of water at various temperatures on the stress-strain relations of rayons.

13 "The average deviations in the strength results of the multiple-strand method seem to be within the sensitivity of the machine (one-half pound); the stretch variations are about three times the possible experimental error caused by the machine." C. W. Schoffstall and H. A. Hamm, B. S. Jour. Research, 2, p. 879; 1929. 


\section{ACKNOWLEDGMENTS}

The authors are indebted to O. G. Lange for help in designing all special apparatus. Acknowledgment is made to C. W. Schoffstall and W. T. Schreiber for kind suggestions.

Washington, June 12, 1929. 